\title{
Incidence and Predictor of Post-Operative Wound Infection in Patients Underwent Coronary Artery Bypass Grafting
}

Saira Gull*, Imran Hussain, Ajwad Farogh, Shamila Afshan and Madiha Iqbal

Laboratory of Cardiovascular Research, University of Texas at San Antonio, San Antonio, TX 78249, USA

\author{
Received: December 21, 2017; Accepted: January 31, 2018; Published: February 7, 2018 \\ *Corresponding author: Saira Gull, CME Department, Biostatistician at Punjab institute of cardiology, Lahore, Pakistan, Tel: +0092-03004350686; \\ E-mail: cabg120@hotmail.com
}

\begin{abstract}
Objective: To determine the incidence and predictor of postoperative wound infection in patients underwent coronary artery bypass grafting ( $\mathrm{CPB})$.

Methods: This was a prospective comparative study of 577 patients who underwent cardiac surgery with (CPB) was conducted at cardiac surgery department of Punjab Institute of cardiology, Lahore from 1st March 2012 to 31st March 2017. Consecutive patients undergoing elective and isolated CABG, both genders age $\geq 20$ years, with normal ejection fraction were included in the study

Results: Out of 577 patients of which 166(87.83\%) were male while $23(12.16 \%)$ were female. The mean age of the patient was $53.23 \pm 8.43$. Incidence of post-operative wound infection in patients underwent coronary artery bypass grafting (CPB) was 73(12.65\%). Common co morbid conditions were hypertension $50 \%$, diabetes mellitus (43.5\%), smoking (31.1\%), hyperlipidemia (20.3\%), prior of stoke $(12.2 \%)$, Prior Surgery $(6.8 \%)$ and prior renal failure $(4.1 \%)$, mean CPB time ( $61.69 \pm 32.27)$, ICU stay $976.03 \pm 31.93)$, mean Cross clamp time $(25.27 \pm 19.17 \mathrm{mg} / \mathrm{dl})$ and Hospital stay $(10.16 \pm 5.6$ day) were more in WI group. Themortality was found to be high in WI group (23.3\%). Logistic regression showed that significantly predicted of the post-operative WI were elder age,diabetes mellitus, smoking, family history of IHD, hyperlipidemia, cardiopulmonary bypass time, ICU stay, hospital stay.
\end{abstract}

Conclusion: We can conclude that wound infected patients are at significantly greater risk of incidence, morbidity and mortality after cardiac surgery.

Keywords: Coronary Artery Bypass Graft; Coronary artery disease; Ischemic heart disease; Wound infection; Nork-Marash Medical Center; Cardiopulmonary bypass;

\section{Introduction}

Coronary Artery Bypass Graft (CABG) is the most common surgery for the treatment of Coronary Artery Disease (CAD) worldwide [1]. Patients undergoing CABG surgery with coronary artery disease are more frequent to have co-morbidities that can lead to complications with non-desired outcomes while one of the vital complications of CABG is sternal wound infection $[2,3]$.

Wound infection is life- threatening complication associated with an increased risk of short and long term morbidity and mortality in patient undergoing (CABG) surgery $[4,5]$. According to the Nork-Marash Medical Center (NMMC), the new cases of wound infection are $7.4 \%$ in patients after CABG, a further study found to be range from $1-10 \%[3,5]$. Which cause mortality of nearly $25 \%$. Furthermore sternal wound infection $25 \%$ and deep sternal wound infection $33 \%$ with a composite morbidity rate of $13.4 \%$ were diagnosed between 30 to 90 days after surgery [6, $7,8]$.

Several studies have suggested that important predictive risk factors may be associated with more likelihood of developing wound infection $[5,9,10]$. Pre and intra-operative predictors are significantly associated withthe increase risk of wound infection. Although in the advance revolution of cardiac surgery the optimization/development of sternal wound infectionsisless decreased [11].

The frequency of Mortality in both WI and non-WI groups in developing countries may vary from the ones mentioned in international literature as there exist differences. So we want to conduct a study to identify the predictors of WI in hospitalized elderly patients who underwent CABG that might help us to do some invasive treatment to reduce its consequences and minimization of hospital stay and cost and mortality rate of CABG.

\section{Data Collection Procedure}

This was a prospective comparative study of 577 patients who underwent cardiac surgery with Cardiopulmonary Bypass (CPB) was selected by using non probability purposive sampling technique, was conducted at cardiac surgery department of Punjab Institute of cardiology, Lahore from $1^{\text {st }}$ March 2012 to $31^{\text {st }}$ March 2017. Patients undergoing elective and isolated CABG, both genders age $\geq 20$ years, with normal ejection fraction (LVEF $\geq 50 \%$ ) were included in the study while patient with emergency CABG, prior history of cardiac operation and MI, calcification in aortic wall, carotid artery disease were excluded from the study.

Data was collected retrospectively. All operations were performed by same surgeon. Routine CABG was done under mild hypothermia $\left(28^{\circ} \mathrm{C}\right)$ with both ante grade and retrograde blood cardioplegia. No topical epicardial cooling is used at our institution. 
Myocardial protection was provided by intermittent coronary perfusion with tapeid blood cardioplegia and continuous topical hypothermia with cold saline. Distal anastomoses were performed during a period of aortic cross-clamping; complete revascularization (e.g. bypass of every vessel with $>50 \%$ stenosis) was attempted in all patients using at least one internal mammary artery as a graft conduit. Proximal venous anastomoses were constructed while the patient was rewarmed. The sternotomy wound was then closed in layers and patients were shifted to the Intensive Care Unit. Intra aortic balloon counter pulsation was used when required. All patients were subjected to postoperative echocardiography to record LV function.

Wound infection was defined as, Superficial Sternal (including sternal SSI, leg SSI, double SSI and both sternum and leg)Wound Infection (SSWI) (an infection involving only skin or subcutaneous tissue at the incision site) while deep sternal wound infection (DSWI) was defined using the guidelines of the Centers for Disease Control and Prevention, i.e., an infection involving tissue spaces beneath the subcutaneous tissue, and patients meeting at least one of the following criteria were diagnosed as having Deep Sternal Wound Infection (DSWI): (1) an organism was isolated from culture of mediastinal tissue or fluid; (2) evidence of mediastinitis was seen during operation; or (3) chest pain, sternal instability, or fever $\left(>38^{\circ} \mathrm{C}\right)$ was present. 12 In-hospital mortality (defined as any death occurring within 30 days of operation)

\section{Statisticla Analysis}

Data was entered in statistical Package for the Social Sciences (SPSS) version 21.0. Quantitative variables were expressed as Mean \pm S.D while for qualitative variables Frequencies, percentages were applied. Qualitative variables comparisons were made with chi-square tests (if cell frequency is less than 5 then fisher exact test applied) while for quantitative variables independent sample test as appropriate. Identify high-risk patients for post-operative wound infection patients who underwent CABG were analyzed by using Logistic regression. Level of statistical significance was considered $\leq 5 \%$. All tests applied were two tailed.

\section{Results}

Out of 577 patients of which 508(88.04\%) were male while $69(11.95 \%)$ were female. In WI group, 63(86.3\%) patients were males and $10(13.7 \%)$ patients were females while in the Non WI group 445(88.3\%)patients were males and 59(11.7\%)were female patients, thus both groups had more male cases than female, ( P-value > 0.05) [table 1]. The mean age presentation in WI group was $54.23 \pm 8.43$, in non WI group was $51.57 \pm 7.06$ years. Both groups showed significant variation with respect to age. The incidence of post operative wound infection is $73(12.65 \%)$ in patients underwent CABG.

Hypertension was found to be slightly similar co morbid conditions in patients who developed WI was $50 \%$, as compare to

Table 1: Demographical of patients underwent coronary artery bypass grafting

\begin{tabular}{|c|c|c|c|c|}
\hline & \multirow[b]{2}{*}{ Variable } & \multicolumn{2}{|c|}{ Groups } & \multirow[t]{2}{*}{ P-value } \\
\hline & & $\begin{array}{l}\text { With wound infection } \\
\quad \mathrm{n}=73(12.65 \%)\end{array}$ & $\begin{array}{l}\text { Without wound } \\
\text { infection } \\
n=504(87.35 \%)\end{array}$ & \\
\hline \multirow{2}{*}{ Gender } & Male & $63(86.3 \%)$ & $445(88.3 \%)$ & \multirow{2}{*}{0.624} \\
\hline & Female & $10(13.7 \%)$ & $59(11.7 \%)$ & \\
\hline \multicolumn{2}{|l|}{ Age } & $54.23 \pm 8.43$ & $51.57 \pm 7.06$ & 0.0235 \\
\hline \multicolumn{2}{|l|}{ Weight } & $75.29 \pm 16.29$ & $74.29 \pm 11.9$ & 0.760 \\
\hline \multicolumn{2}{|l|}{ Height } & $161.30 \pm 23.3$ & $167.30 \pm 11.8$ & 0.026 \\
\hline \multicolumn{2}{|c|}{ Hypertension } & $36(49.3 \%)$ & $252(50 \%)$ & 0.913 \\
\hline \multicolumn{2}{|l|}{ Diabetes } & $30(41 \%)$ & $144(28.54 \%)$ & $0.0411 \#$ \\
\hline \multicolumn{2}{|l|}{ Smoking } & $24(32.9 \%)$ & $108(21.42 \%)$ & $0.0462 \#$ \\
\hline \multicolumn{2}{|c|}{ Prior history of stoke } & $5(6.84 \%)$ & $5(0.99 \%)$ & $0.003^{*}$ \\
\hline \multicolumn{2}{|c|}{ Hyperlipidemia } & $17(23.3 \%)$ & $68(13.5 \%)$ & $0.027 \#$ \\
\hline \multicolumn{2}{|c|}{ Prior history of Renal Failure } & $5(6.8 \%)$ & $6(1.2 \%)$ & $0.001^{*}$ \\
\hline
\end{tabular}

non-WI group (49.3\%). Diabetes mellitus (58.12\% vs. $34.78 \%)$, smoking (31.1\% vs. 17.39\%), Hyperlipidemia (20.3\% vs. $12.2 \%$ ), Prior of stoke (12.2\% vs. $0.9 \%$ ), Prior Surgery (6.8\% vs. $4.3 \%$ ) and Prior Renal Failure (4.1\% vs.1.7) were more commonly observed in WI group as compare to non-WI group.
Mean CPB time and mean pre-operative creatinine and mean per $\mathrm{EF}(\%)$ were significantly associated with WI group (63.76 \pm $34.93 v s .78 .29 \pm 32.03)$ and $(1.3 \pm 0.27$ vs. $1.0 \pm 0.48)$ and $(42.33 \pm$ $9.3 \%$ vs. $49.63 \pm 10.7 \%$ ) as compare to non-WI group. Mean Cross clamp time level and Hospital staywere insignificantly associated 
with WI group ( $20.88 \pm 12.11 \mathrm{vs} .18 .57 \pm 9.03) \mathrm{mg} / \mathrm{dl}$ and $(11.37$ \pm 7.91 vs. $12.08 \pm 5.79$ ). The trend towards mortality was greater in WI group as compare to non-WI group (23.3\% vs. $6.1 \%$ ).

Logistic regression reported that of preoperative risk factors elder age (OR: 1.021,CI 95\%:0.987-1.057), height (OR:1.021,CI 95\%:1.003-1.036), diabetes mellitus (OR:1.21,CI 95\%:0.647-
2.294), smoking (OR:1.051,CI 95\%:0.533-2.073), prior history of stoke (OR:1.03,CI 95\%:0.539-2.073), hyperlipidemia (OR:1.82,CI 95\%:0.858-3.889), prior history of renal failure (OR:1.773,CI 95\%:0.236-3.299), cardiopulmonary bypass time(OR:1.007,CI 95\%:0.956 -1.060), pre EF (\%) (OR: 1.019, CI 95\%:0.951-1.092) and Pre Blood serum creatinine (OR: 1.785, CI 95\%:0.523 -1.179) were significantly predicted post-operative WI. [Table 2, 3]

Table 2: Association of Pre, Intra and post-operative patient characteristics with and without wound infection in patients undergoing CABG

\begin{tabular}{|c|c|c|c|}
\hline \multirow[b]{2}{*}{ Variables } & \multicolumn{2}{|c|}{ Groups } & \multirow[b]{2}{*}{ P-value } \\
\hline & With wound infection $\mathrm{n}(73)$ & $\begin{array}{l}\text { With wound infection } \\
n(504)\end{array}$ & \\
\hline Pre EF & $42.33 \pm 9.3$ & $49.63 \pm 10.7$ & 0.001 \\
\hline CPB time & $63.76 \pm 34.93$ & $78.29 \pm 32.03$ & 0.006 \\
\hline Cross clamp time & $20.88 \pm 12.11$ & $18.57 \pm 9.03$ & 0.143 \\
\hline Pre-operative Creatinine & $1.3 \pm 0.27$ & $1.0 \pm 0.48$ & 0.011 \\
\hline Hospital stay & $11.37 \pm 7.91$ & $12.08 \pm 5.79$ & 0.371 \\
\hline Mortality & $17(23.3 \%)$ & $7(6.1 \%)$ & 0.001 \\
\hline
\end{tabular}

Table 3: Logistic regression model for Predictors associated with post-operative wound

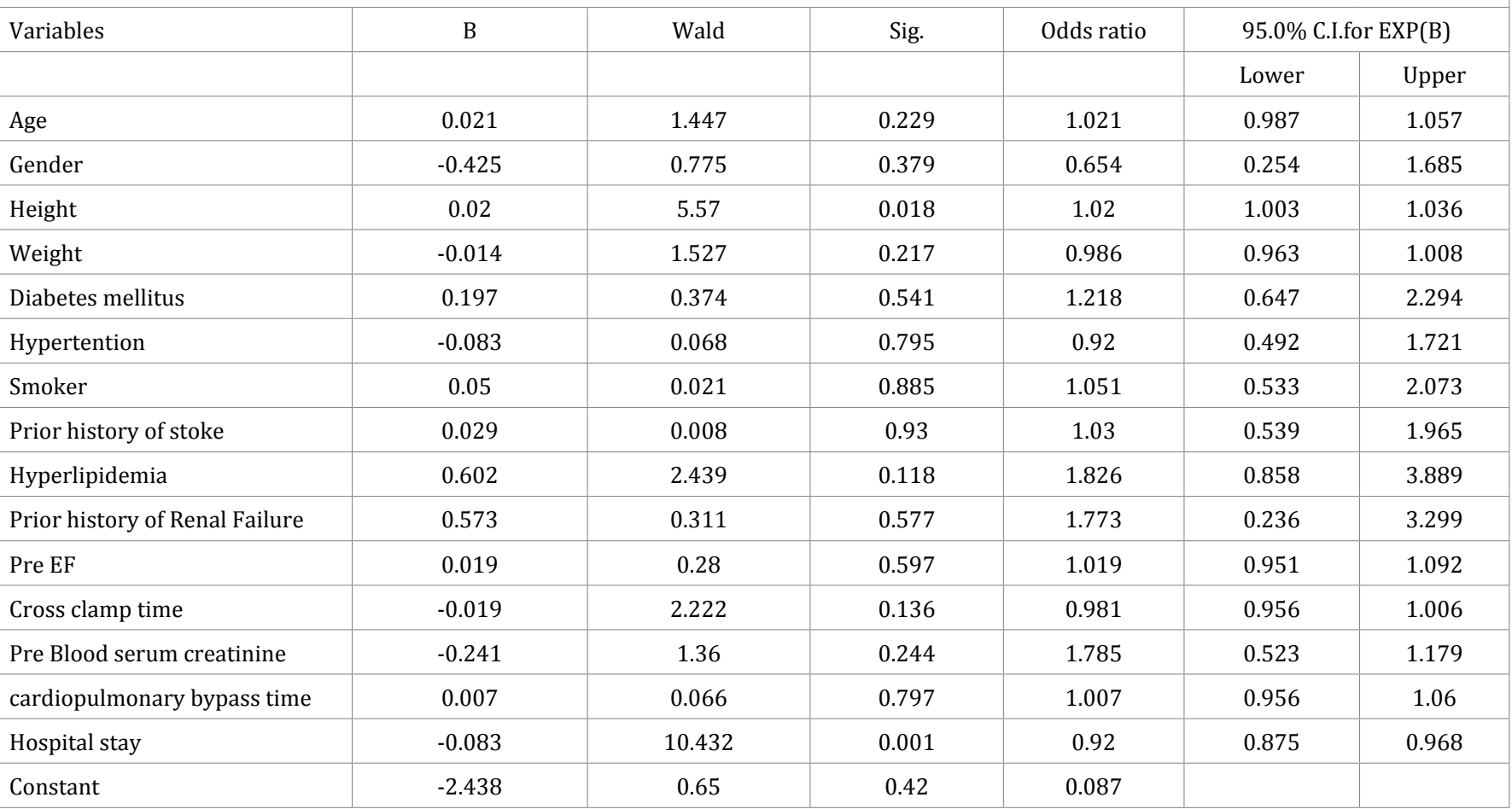

\section{Discussion}

Present study reported that incidence of Wlin patients underwent CABG was somewhat higher than in other studies as (12.65\%). Ahmed D [16] and Ridderstolpe L, et al. [5] reported incidence rate of WI was $12.64 \%$ and $16.1 \%$. JY Bhatia, et al. [15] demonstrated high rate of incidence rate of WI in patients underwent CABG as (18.86\%). Kay AE [13] and Omran AS, et al. [14] found that incidence of WI was $24.4 \%$. This dissimilarity was due to differences in the sample size of the present study.
Our results showed that male group of WI patients were higher indicating that men are at increased risk of post-operative WI (89.2\% vs. $10.2 \%)$. McConkey SJ [12], Borger MA [9] and Stahle E, et al. [10] found that WI was more in male than female (84.4\% vs. $15.6 \%$ ). Omran AS, et al. [14] established that WI is more prevalent in male patients compared to female patients (74.5\% vs. $25.5 \%$ ). Another study by Hoseini MJ, et al. [17] found that WI was more in male than female ( $99.8 \%$ vs. $0.2 \%)$, due to bias in selection of female patient. 
The present study examined that the average age of the patient who developed WI underwent CABG was $54.23 \pm 8.43$ years. Sajja LR, et al. [18] found that average age of the patient was $57.8 \pm 7.43$ years. Omran AS, et al. [14] demonstrated that the average age of the patient was $58.5 \pm 9.7$ years. Ridderstolpe $\mathrm{L}$, et al. [5] reported that average age of the patient was $65.4 \pm 10.5$ years. In contrast with these studied present study showed dissimilar result may be due to small sample size. Magedanz EH [22] and Discigil G, et al. [23] reported that age was anindependent predictors of WI as $(61 \pm 10.1$ years; $\mathrm{OR}=2.1)$.

Present study reported thatpost-operative WI was independently associated with a higher 30-day mortality rate (23.3\% vs. 6.1\%). Kubota $\mathrm{H}$, et al. [19] reported that postoperative WI was independently associated with a higher 30-day mortality rate (25.8\% vs. $9.7 \%$ ). Omran AS et al. [14] determined in-hospital mortality was found to be high in WI group as compare to non-WI group as (14\% vs. 1.1\%) Ridderstolpe L, et al. [5] established that 30 day mortality rate was higher for all patients without WI group as compared to WI group $(2.7 \%$. vs. $0.7 \%$ ). Lu JC, et al. [21] established that 30 day mortality rate was higher for all patients without WI group as compared to WI group (25.5\%.vs. $2.5 \%)$.

Present study reported that diabetes is one of the major confounder for wound infection after CABG as diabetes mellitus has been attributed to the impairment of neutrophil chemotaxis, phagocytosis, adherence plus the glycosylation of collagen matrix proteins - all of which lead to weakened antibacterial defenses and delayed wound healing.

Borger MA, et al. [9] scrutinized that Independent predictors of WI were diabetes mellitus (OR: 2.6) and male sex (OR: 2.2).

Ridderstolpe L, et al. [5] examined that independent predictors of WI were diabetes mellitus age (OR: 1.90), smoking (OR: 1.39), prolonged ICU stay (OR: 1.004) Peivandi AA, et al. [20] found that independent predictors of WI werediabetes (OR $=4.130)$, smoking history $(\mathrm{OR}=2.996)$, old age $(\mathrm{OR}=1.108)$ Omran AS, et al. [14] reported that independent risk factors of WI werehypertension $(\mathrm{OR}=10.7)$, and female gender $(\mathrm{OR}=2.7)$. In contrast with the previous literature present study reported that the independent variables for predicting wound infection were elder age (OR:1.514), diabetes mellitus (OR:1.94), smoking (OR:4.91), family history of IHD(OR:5.42), hyperlipidemia (OR:9.97), cardiopulmonary bypass time(OR:1.02), ICU stay (OR:7.41) and hospital stay (OR:1.15). Recent study indicated changed outcomes due to predictors recognized in single center may be differing in another institute, mainly due to changes in protocol of care.

To avoid versus conditions after CABG operation due to infection, an early and aggressive management is needed for defining superficial and deep sternal infections. The most appropriate use of date of current research is timely feedback to concerned person as this lead to increased awareness and knowledge about patients.

\section{Conclusion}

We can conclude that wound infected patients are at significantly greater risk of incidenceand mortality after cardiac surgery due to the combination of contributors.

\section{References}

1. Lawrence H.Cohn. Cardiac surgery in the adult. Third edition ed. McGraw HillMedical, 2008.

2. Jenney AW, Harrington GA, Russo PL, Spelman DW. Cost of surgical site infections following coronary artery bypass surgery. ANZ J Surg. 2001;71(11):662-664.

3. NazaryanInessa. Epidemiological Characteristics of Surgical Site infection in Cardiosurgical Hospital. Ministry of Health, RA, National Institute of Health after S. Avdalbekyan, 2008.

4. Kimberly Singh, Erica Anderson, J. Garrett Harper. Overview and Management of Sternal Wound Infection. Semin Plast Surg. 2011;25(1):25-33.

5. Ridderstolpe L, Gill H, Granfeldt H, Ahlfeldt H, Rutberg H. Superficial and deep sternal wound complications: incidence, risk factors and mortality. Eur J Cardiothorac Surg. 2001;20:1168-1175.

6. Hollenbeak CS, Murphy DM, Koenig S, Woodward RS, Dunagan WC, Fraser VJ. The clinical and economic impact of deep chest surgical site infections followingcoronary artery bypass graft surgery. Chest. 2000;118(2):397-402.

7. Jonkers D, Elenbaas T, Terporten P, Nieman F, Stobberingh E. Prevalence of 90-days postoperative wound infections after cardiac surgery. European Journal of Cardio-thoracic Surgery. 2003;23(1):97-102.

8. Shroyer AL, Coombs LP, Peterson ED, Eiken MC, De-Long ER, Chen A, et al. The Society of Thoracic Surgeons: 30-day operative mortality and morbidity risk models. Ann Thorac Surg. 2003;75(6):1856-1864.

9. Borger MA, Rao V, Weisel RD, Ivanov J, Cohen G, Scully HE, et al. Deep sternal wound infection: risk factors and outcomes. Ann Thorac Surg. 1998;65:1050-1056.

10. Stahle E, Tammelin A, Bergstrom R, Hambreus A, Nystrom SO, Hansson HE. Sternal wound complications incidence, microbiology and risk factors. Eur J Cardiothorac Surg. 1997;11(6):1146-1153.

11. Singh K, Anderson E, Garrett Harper J. Overview and Management of Sternal Wound Infection. Semin Plast Surg 2011;25:25-33.

12. McConkey SJ, L’Ecuyer PB, Murphy DM, Leet TL, Sundt TM, Fraswe VJ. Results of a comprehensive infection control program for reducing surgical-site infections in coronary artery bypass surgery. Infection control and hospital epidemiology. 1999;20(8):533-538.

13. Reid R, Simcock JW, Chisholm L, Dobbs B, Frizelle FA. Postdischarge clean wound infections: incidence underestimated and risk factors overemphasized. ANZ journal of surgery. 2002;72(5):339-343.

14.0mran AS, Karimi A, Ahmadi SH, Davoodi S, Marzban M, Movahedi $\mathrm{N}$, et al. Superficial and deep sternal wound infection after more than 9000 coronary artery bypass graft (CABG): incidence, risk factors and mortality. BMC infectious diseases. 2007;7(1):112. DOI: 10.1186/1471-2334-7-112 
15. Bhatia JY, Pandey K, Rodrigues C, Mehta A, Joshi VR. Postoperative wound infection in patients undergoing coronary artery bypass graft surgery: a prospective study with evaluation of risk factors. Indian journal of medical microbiology. 2003;21(4):246-251.

16. Ahmed D, Cheema FH, Ahmed YI, Schaefle KJ, Azam SI, Sami SA, Sharif HM. Incidence and predictors of infection in patients undergoing primary isolated coronary artery bypass grafting: a report from a tertiary care hospital in a developing country. The Journal of cardiovascular surgery. 2011;52(1):99-104.

17. Hoseini MJ, Naseri MH, Teimoori M. Investigation of Deep Sternal wound infection after coronary artery bypass graft and its risk factors. PAKISTAN JOURNAL OF MEDICAL SCIENCES. 2008;24(2):251.

18. Sajja LR, Mannam G, Dandu SB, Sompalli S. Reduction of sternal wound infections in diabetic patients undergoing off-pump coronary artery bypass surgery and using modified pedicle bilateral internal thoracic artery harvest technique. The Journal of thoracic and cardiovascular surgery. 2012;144(2):480-485. DOI: 10.1016/j.jtcvs.2012.03.024
19. Kubota H, Miyata H, Motomura N, Ono M, Takamoto S, Harii K, et al. Deep sternal wound infection after cardiac surgery. Journal of cardiothoracic surgery. 2013;8(1):132. DOI: 10.1186/1749-8090-8132

20. Peivandi AA, Kasper-König W, Quinkenstein E, Loos AH, Dahm M. Risk factors influencing the outcome after surgical treatment of complicated deep sternal wound complications. Cardiovascular Surgery. 2003;11(3):207-212.

21. Lu JC, Grayson AD, Jha P, Srinivasan AK, Fabri BM. Risk factors for sternal wound infection and mid-term survival following coronary artery bypass surgery. European journal of cardio-thoracic surgery. 2003;23(6):943-949.

22. Magedanz EH, Bodanese LC, Guaragna JCVC, Albuquerque LC, Martins V, Minossi SD, et al. Elaboração de escore de riscoparamediastinitepóscirurgia de revascularização do miocárdio. Rev Bras Cir Cardiovasc. 2010;25(2):154-9.

23. Discigil G, Ozkisacik EA, Badak MI, Günes T, Discigil B. Obesity and open-heart surgery in a developing country. Anadolu Kardiyol Derg. 2008;8(1):22-26. 